\title{
Treatment of textile wastewater by Fenton's process as a Advanced Oxidation Process
}

\author{
Amruta D. Patil ${ }^{1}$, Prof. Dr. P. D. Raut ${ }^{2}$ \\ ${ }^{I}$ (Student,M.Tech (Env.Sci. and Tech), Department of Env.Sci. and Tech, Shivaji University ,Kolhapur (MH) \\ ${ }_{2}^{2}$ (Professor, Department of Env. Science, Shivaji University, Kolhapur (MH)
}

\begin{abstract}
Textile manufacturing is a major industry. These are then fabricated into cloth. There are many variable processes are available at spinning and fabric forming stages coupled with complexities of finishing and coloration processes to production of wide ranges of products. All the processes generate considerable volume of effluents and hence, forms major source of wastewater containing organic and inorganic substances. Thus, Fenton reagent is an oxidative decomposition and transformation of organic substrates by $\mathrm{H}_{2} \mathrm{O}_{2} / \mathrm{Fe}^{2+}$. Fenton reagent is a result of reaction between hydrogen peroxide $\left(\mathrm{H}_{2} \mathrm{O}_{2}\right)$ and ferrous ion $\left(\mathrm{Fe}^{2+}\right)$ producing hydroxyl radical, and is a strong oxidant capable of oxidizing various organic compounds This process evaluates oxidation and coagulation, for removal of color and Chemical Oxygen Demand (COD) from textile wastewater containing dyes. For effective removal efficiency $\mathrm{pH}$ value should be in the range of 2.5 to 4 . Fenton's reagent has been effective in treating various industrial wastewater and wide variety of dyes. Fenton process gives colour removal efficiency is $98 \%$ at $\mathrm{pH} 3$ at $\mathrm{FeSO}_{4}$ of $0.2 \mathrm{gm} / \mathrm{lit}$. and $\mathrm{H}_{2} \mathrm{O}_{2}$ of $0.1 \mathrm{ml} / \mathrm{lit}$. and COD removal efficiency is $85 \%$ at $\mathrm{pH} 3$ at $\mathrm{FeSO}_{4}$ of $1.2 \mathrm{gm} / \mathrm{lit}$. and dose of $\mathrm{H}_{2} \mathrm{O}_{2}$ of $0.6 \mathrm{ml} / \mathrm{lit}$.
\end{abstract}

Keywords: coagulation, Fenton reagent, ferrous ion, hydrogen peroxide, textile wastewater.

\section{Introduction}

Textile industry consumes large quantities. The various operations involved in cotton textile industry are warping, winding, sizing weaving, dying, padding, steamer, CDR zone, CDR washing, printing, finishing. All this processes generate considerable volume of effluents and forms major source of wastewater containing organic and inorganic substances. Industrial wastewater contains toxic and non-biodegradable compounds that affect effectiveness of conventional treatment techniques. Pollutants in the wastewater coming from raw materials processing, process by-products, process chemicals and final production. Organic, inorganic, color producing dyes, toxic compounds like cyanide and heavy metals, if discharged without any treatment are harmful to aquatic life in water bodyThus, Advanced Oxidation Process (AOP) with Fenton reagent $\left(\mathrm{Fe}^{2+} /\right.$ $\mathrm{H}_{2} \mathrm{O}_{2}$ ) helps to degrade organic compounds presented in polluted water In AOP, hydroxyl radical $(\mathrm{OH})$ are generated in solution and are responsible for oxidation of organic compounds. Hydrogen Peroxide is a multipurpose oxidant for many systems. It can be applied with or without catalyst. Catalyst normally used is ferrous sulphate and other normally used are iron salts, $\mathrm{Al}^{+3}, \mathrm{Cu}^{+2}$.

\section{Introduction To Fenton Process As A Advanced Oxidation Process}

Many physical, biological, and chemical processes are used in wastewater treatment. But some contaminants found in wastewater are recalcitrant to some degree to commonly applied processes. Chemical oxidation processes are transformation processes that may augment current treatment schemes. Oxidation processes may destroy certain compounds and constituents through oxidation and reduction reactions. Advanced oxidation is chemical oxidation with hydroxyl radicals, which are very reactive, and short-lived oxidants..The $\mathrm{COD}$ of the wastewater from the facility needed to be reduced in concentration before discharge to the local public treatment. bodyThus, Advanced Oxidation Process (AOP) with Fenton reagent $\left(\mathrm{Fe}^{2+} / \mathrm{H}_{2} \mathrm{O}_{2}\right)$ helps to degrade organic compounds presented in polluted water In AOP, hydroxyl radical $\left(\mathrm{OH}^{-}\right)$are generated in solution and are responsible for oxidation of organic compounds. Hydrogen Peroxide is a multipurpose oxidant for many systems. It can be applied with or without catalyst. Catalyst normally used is ferrous sulphate and other normally used are iron salts, $\mathrm{Al}^{+3}, \mathrm{Cu}^{+2}$. [1]

\subsubsection{Introduction:}

\section{Material And Methedology}

It has been demonstrated that Fenton's reagent is able to destroy toxic compounds in waste waters such as phenols and herbicides. Production of $\mathrm{OH}$ radicals by Fenton reagent occurs by means of addition of $\mathrm{H} 2 \mathrm{O} 2$ to $\mathrm{Fe} 2+$ salts.[1]

$$
\mathrm{H}_{2} \mathrm{O}_{2}+\mathrm{Fe}^{2+} \rightarrow \mathrm{OH} \bullet+\mathrm{OH}^{-}+\mathrm{Fe}^{3+}
$$


This is a very simple way of producing $\mathrm{OH}$ radicals neither special reactants nor special apparatus being required. This reactant is an attractive oxidative system for waste water treatment due to the fact that iron is very abundant and non toxic element and hydrogen peroxide is easy to handle and environmentally safe. The oxidation using Fenton's reagent has proven a promising and attractive treatment method for the effective decolorization and degradation of dyes [3]. The Fenton system uses ferrous ions to react with hydrogen peroxide, producing hydroxyl radicals with powerful oxidizing abilities to degrade certain toxic contaminants [4]. Hydroxyl radicals may react with ferrous ions to form ferric ions or react with organics:

$$
\begin{gathered}
\mathrm{OH} \bullet+\mathrm{Fe}^{2+} \rightarrow \mathrm{OH}^{\square}+\mathrm{Fe}^{3+} \\
\mathrm{OH} \bullet+\text { organics } \rightarrow \text { products }
\end{gathered}
$$

Hydroxyl radicals can also react with hydrogen peroxide to produce other radicals, and may also combine with each other to produce hydrogen peroxide, which are shown below

$$
\begin{aligned}
& \mathrm{OH} \bullet+\mathrm{H}_{2} \mathrm{O}_{2} \rightarrow \mathrm{H}_{2} \mathrm{O}+\mathrm{HO}_{2} \bullet \\
& \mathrm{OH} \bullet+\mathrm{OH} \bullet \rightarrow \mathrm{H}_{2} \mathrm{O}_{2}
\end{aligned}
$$

Ferrous ions and radicals are produced during the reactions. The reactions are shown in Eqs. (6)-(9)

$$
\begin{gathered}
\mathrm{H}_{2} \mathrm{O}_{2}+\mathrm{Fe}^{3+} \leftrightarrow \mathrm{H}++\mathrm{FeOOH}^{2+} \\
\mathrm{FeOOH} \mathrm{H}_{2}+\underset{\mathrm{HO}_{2} \bullet}{ }+\mathrm{Fe}^{2+} \\
\mathrm{HO} 2 \bullet+\mathrm{Fe}^{2+} \rightarrow \mathrm{HO}_{2}-+\mathrm{Fe}^{3+} \\
\mathrm{HO} 2 \bullet+\mathrm{Fe}^{3+} \rightarrow \mathrm{O}_{2}+\mathrm{Fe}^{2+}+{ }^{\mathrm{H}+}
\end{gathered}
$$

\subsection{Jar Test}

Chemical coagulation were conducted with the help of jar test. Various dosages were used for $\mathrm{Fe}^{2+}$ and $\mathrm{H}_{2} \mathrm{O}_{2}$. the coagulation experiment s proceeded with rapid mixing of wastewater sample at $130 \mathrm{rpm}$ for 2 min, slow mixing at $30 \mathrm{rpm}$ for $18 \mathrm{~min}$, then settling for 30min. after settling, filtration were done . Filtration process is done with the help of whatman filter paper. Then, filtrate taken for COD and colour analyses. After jar test COD and Colour of wastwater samples were measured according to procedures described in APHA standard methods .[2]

\subsection{Fenton process}

Fenton process it is one of the advanced oxidation process.It is the result of reaction between hydrogen peroxide $\left(\mathrm{H}_{2} \mathrm{O}_{2}\right)$ and ferrous sulphate $\left(\mathrm{FeSO}_{4}\right)$ producing hydroxyl radical $(\mathrm{OH}$.) the hydroxyl radical is a strong oxidant capable of oxidizing various organic compounds[3]

\subsubsection{Fenton process Procedure}

Adjust $\mathrm{pH}$ is in between 1 to 7 then add iron catalyst $\left(\mathrm{FeSO}_{4}\right)$ and then adding slowly hydrogen peroxide $\left(\mathrm{H}_{2} \mathrm{O}_{2}\right)$ Then Jar test was done to mix the $\mathrm{FeSO}_{4}$ and $\mathrm{H}_{2} \mathrm{O}_{2}$ dosages.. Then settling time 30 minute kept for settlement afterwards $\mathrm{pH}$ range 1-7 was taken as well as varying dosages $\mathrm{FeSO}_{4}$ and $\mathrm{H}_{2} \mathrm{O}_{2}$ to determine optimum $\mathrm{P}^{\mathrm{H}}$ for COD and colour removal. from that investigated optimum $\mathrm{P}^{\mathrm{H}}$ from that $\mathrm{pH}$, keeping $\mathrm{H}_{2} \mathrm{O}_{2}$ dose of $1.1 \mathrm{ml}$, calculated optimum removal of $\mathrm{FeSO}_{4}$ dose for COD and colour removal. Then, kept $\mathrm{FeSO}_{4}$ dose constant $1.2 \mathrm{gm}$, calculated optimum dose of $\mathrm{H}_{2} \mathrm{O}_{2}$ for COD and colour analysis.

\section{Result And Discussion}

5.1 General characteristics of textile industry are shown in table 1.

Table 1 - general characteristics of textile industry

\begin{tabular}{|l|l|l|l|}
\hline Sr.no. & Parameters & Inlet /raw & After treatment \\
\hline 1 & $\mathrm{P}^{\mathrm{H}}$ & $10-12$ & $6.5-8.5$ \\
\hline 2 & COD & $1800-2000 \mathrm{mg} / \mathrm{lit}$ & $800-1000 \mathrm{mg} / \mathrm{lit}$ \\
\hline 3 & BOD & $800-875 \mathrm{mg} / \mathrm{lit}$ & $300-150 \mathrm{mg} / \mathrm{lit}$ \\
\hline 4 & Colour & 1.9800 & 0.8400 \\
\hline
\end{tabular}


5.2 Determination of optimum $\mathrm{pH}$ for colour as well as for COD reduction removal in (\%).
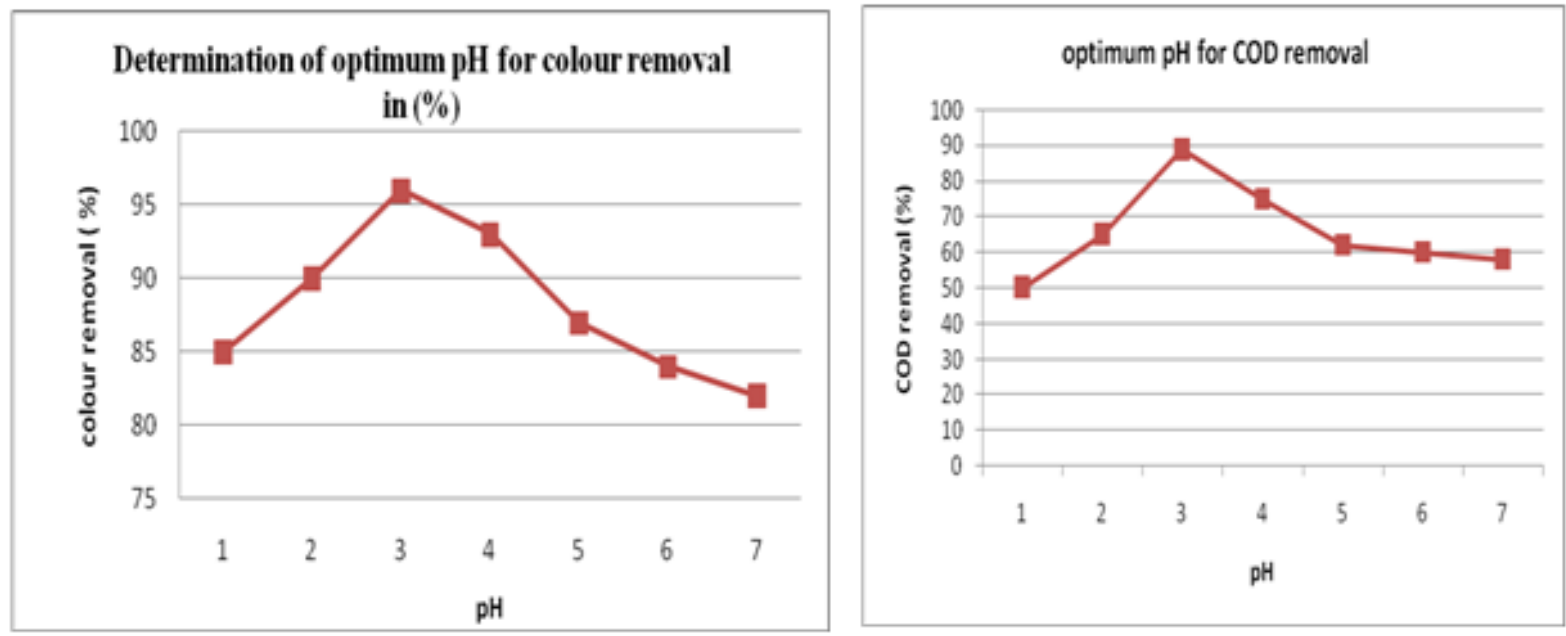

Fig 1 and fig.2 shows that, optimum removal efficiency for colour and COD . optimum removal efficiency of colour obtained is $96 \%$ at $\mathrm{pH}=3$. By varying dosages of $\mathrm{H}_{2} \mathrm{O}_{2}$ from 0.1-0.6 (ml/lit.) and $\mathrm{FeSO}_{4}$ from $0.2-1.2$ ( $\mathrm{gm} / \mathrm{lit}$.). optimum removal efficiency of COD obtained is $89 \%$ at $\mathrm{pH}=3$. By varying dosages of $\mathrm{H}_{2} \mathrm{O}_{2}$ from 0.1 0.6 (ml/lit. )and FeSO from $0.2-1.2$ (gm/lit.).

\subsection{Determination of Optimum $\mathrm{H}_{2} \mathrm{O}_{2}$ dose for Colour and COD removal}
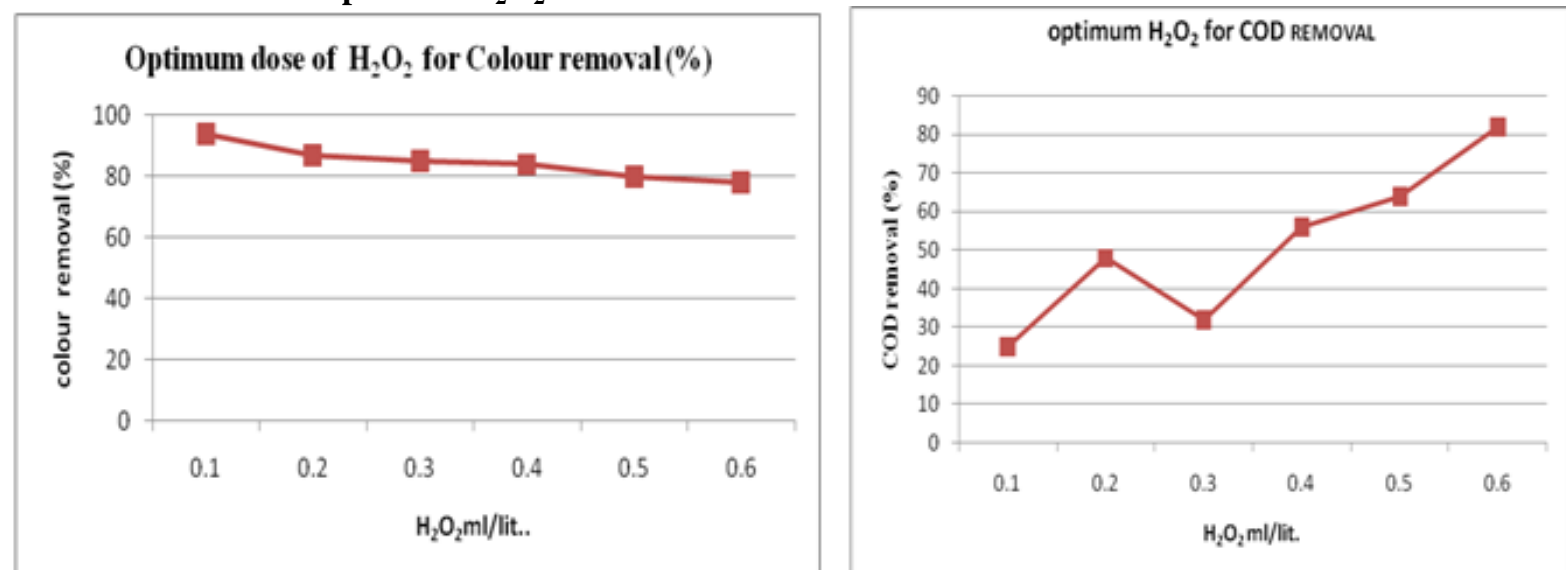

Fig 3 and fig 4 shows that, the optimum $\mathrm{H}_{2} \mathrm{O}_{2}$ dose for colour removal is $0.1 \mathrm{ml} / \mathrm{lit}$. and for COD removal 0.6 $\mathrm{ml} /$ lit.from the graph it can be shows that, as $\mathrm{H}_{2} \mathrm{O}_{2}$ dose increases colour removal efficiency decreses and COD removal efficiency increases.

\subsection{Determination of Optimum $\mathrm{H}_{2} \mathrm{O}_{2}$ dose for Colour and COD removal}
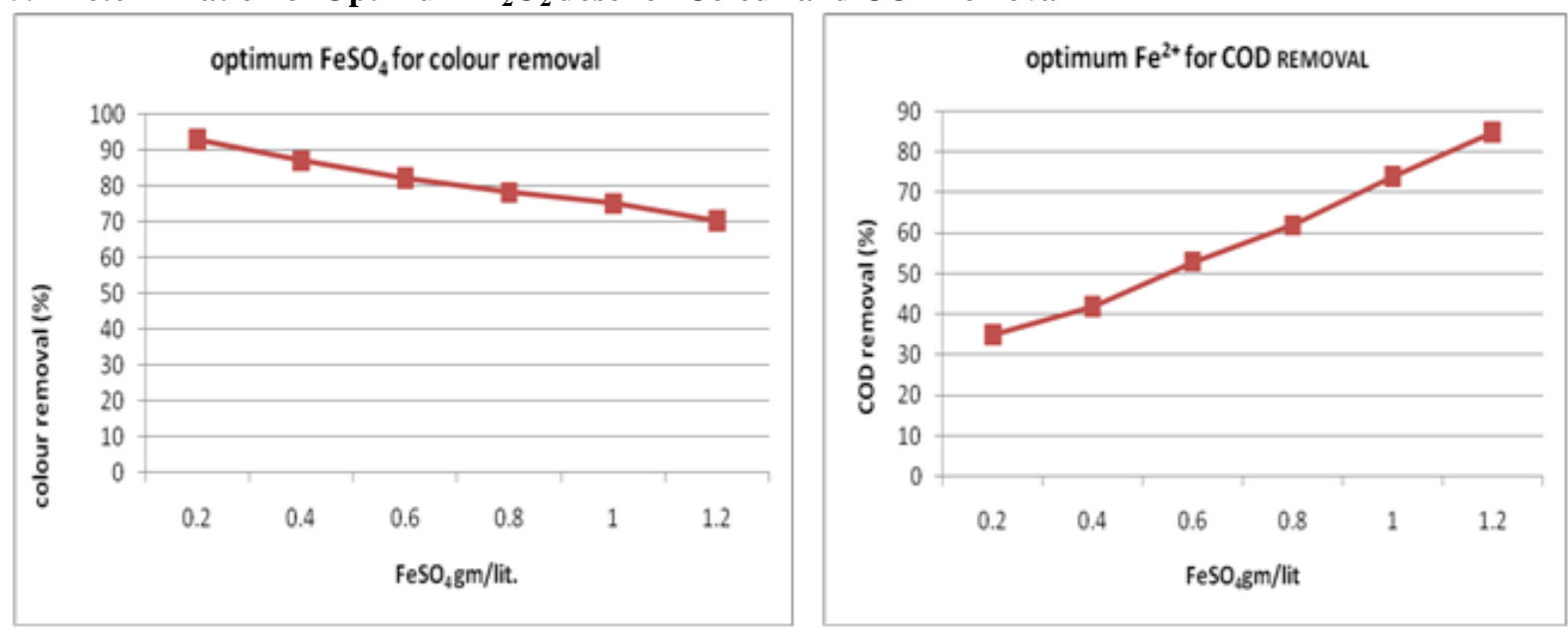
Fig 4 and 5 shows that, optimum FeSO4 dose for colour removal is at $0.2 \mathrm{gm} / \mathrm{lit}$. and for COD removal is 1.2 $\mathrm{gm} / \mathrm{lit}$. from graph it can be shown that, as dose increases colour removal efficiency decreases and COD removal efficiency increases.

\subsection{Determination of comparison between Fenton process and ferric coagulation for}

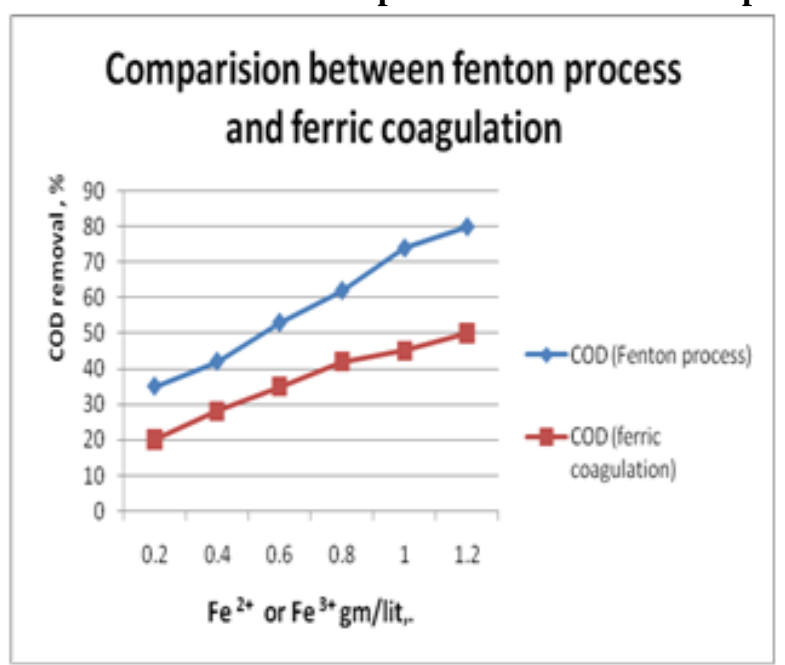

Fig 7 shows that, COD with Fenton process with ferric coagulation

\section{effect of settling time on colour and COD removal}

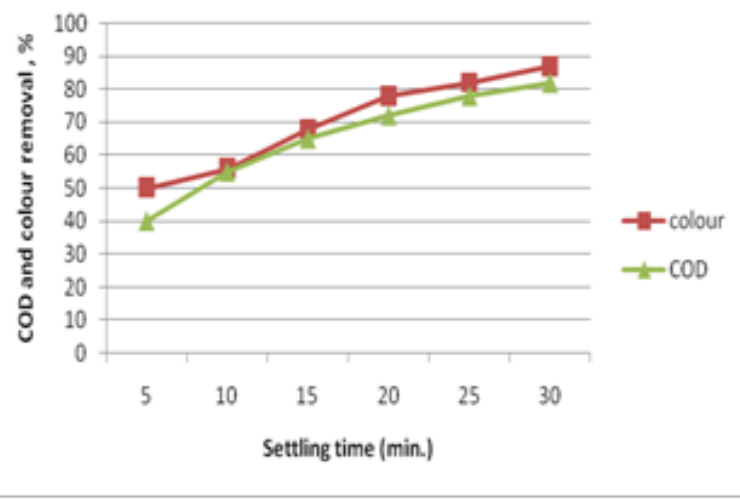

fig 8 shows that, effect of settling time

\subsection{To compare chemical cost of Fenton's reagent doses.}

Table 2 chemical cost of Fenton process

\begin{tabular}{|l|l|l|}
\hline \multicolumn{1}{|c|}{ Chemical cost } & Dose requirement & Cost required \\
\hline $\mathrm{FeSO}_{4}=192 /-($ per $500 \mathrm{gm})$ & 16 & 3072 \\
\hline $\begin{array}{l}\mathrm{H}_{2} \mathrm{O}_{2}=360 /-(\text { per } 500 \mathrm{ml}) \\
30 \% \text { purity }\end{array}$ & 12 & 4320 \\
\hline total & - & $8640 /-$ \\
\hline
\end{tabular}

\section{Conclusion}

Advanced Oxidation Process (AOP) has superior performance for COD reduction compared to ferric coagulation process means $\mathrm{FeSO}_{4}$ used as coagulant. Fenton process gives colour removal efficiency is $98 \%$ at $\mathrm{pH}=3$ keeping optimum dose of $\mathrm{FeSO}_{4}=0.2 \mathrm{gm} / \mathrm{lit}$. and dose of $\mathrm{H}_{2} \mathrm{O}_{2}=0.1 \mathrm{ml} / \mathrm{lit}$. and for COD $89 \%$ at $\mathrm{pH}=3$ keeping optimum dose of $\mathrm{FeSO}_{4}=1.2 \mathrm{gm} / \mathrm{lit}$. and dose of $\mathrm{H}_{2} \mathrm{O}_{2}=0.6 \mathrm{ml} / \mathrm{lit}$.From the results it can be conclude that, as dosages of $\mathrm{FeSO} 4$ and $\mathrm{H}_{2} \mathrm{O}_{2}$ increases the removal efficiency of colour get decreases and as dosages of FeSO4 and $\mathrm{H}_{2} \mathrm{O}_{2}$ increases the removal efficiency of COD get increases. From above it can be concluding that, for colour reduction the dosages are inversely proportional to the efficiency in \%.and for COD reduction dosages are directly proportional to efficiency in \%.Fenton process gives more efficiency than ferric coagulation in COD removal efficiency. It can be seen that, removal efficiency of colour by Fenton process requires relatively low dosages of $\mathrm{H}_{2} \mathrm{O}_{2}$ and $\mathrm{FeSO}_{4}$, whereas much higher dosages of $\mathrm{H}_{2} \mathrm{O}_{2}$ and $\mathrm{FeSO}_{4}$ are nessecery to obtain COD removal.

\section{Acknowledgements}

This is for the firm assertion of the concerned authorities that the dissertation work entitled "Treatment of textile wastewater by Fenton's process as a Advanced Oxidation Process" has been completed by the undersigned strictly on an individual basis for the fulfillment of the requirements for the award of "Master of Technology" in Environmental Science and Technology, under Shivaji University, Kolhapur, during the year 2013-2014.

\section{References}

[1]. Perkowski Jan and Kos Lech (2002), 'Treatment of textile dyeing wastewater by hydrogen peroxide and ferrous ions. The journal of fibres and textiles in Eastern Europe.

[2]. "Standard Methods for the Examination of Water and Wastewater". (2005). 20th ed., American Public Health Association, APHA/AWWA/WPCF, Washington.

[3]. Meric Sureyya, Kaptan Deniz, Olmez Tugba, (2004). Color and COD removal from wastewater containing reactive black 5 using Fenton's oxidation process. The journal of Elsevier. Chemosphere 54, 435-441.

[4]. Kang et al., (2002). Pre-oxidation and coagulation of textile wastewater by the Fenton process'. The journal of Elsevier. Chemosphere 46, 923-928.

[5]. Lin, S.H., Peng, C.F., 1995. A continuous Fenton's process for treatment of textile wastewater. Environ. Technol. 16, 693-699. 